\title{
A QUALIDADE DE UMA PESQUISA EM EDUCAÇÃO: CONCEPÇÕES EXPRESSAS POR REAMEQUIAN@S, TURMA 2019
}

\author{
THE QUALITY OF A RESEARCH IN EDUCATION: CONCEPTIONS EXPRESSED \\ BY REAMEQUIAN @ S, CLASS 2019
}

Kênya Maria Vieira Lopes ${ }^{1}$

ORCID iD: 0000-0001-5930-5464

Marta Maria Pontin Darsie ${ }^{2}$

ORCID iD: $\underline{0000-0002-1255-6546}$

\begin{abstract}
RESUMO
O presente artigo busca apresentar algumas das concepções sobre a qualidade de uma pesquisa em educação expressas por reamequian@ @ no percurso da disciplina de Pesquisa em Ciências da Educação do Doutorado em Educação em Ciências e Matemática da REAMEC, Universidade Federal de Mato Grosso, em 2019. O instrumento-base de coleta de dados para a produção deste trabalho foi um questionário proposto aos colegas reamequian@s em uma atividade prática desenvolvida com a turma durante a socialização de um texto que aborda rigor e qualidade de pesquisa em educação. A análise dos dados pautou-se em Bardin. Entre os resultados apresentados pel@s doutorand@s sobre o que deve ter uma pesquisa para ela ser considerada de qualidade, constaram conceitos que envolviam: confiabilidade, imparcialidade, relevância, valores morais e éticos, princípios/rigor científicos, análise dos caminhos da educação, contribuições do resultado da pesquisa para o processo educativo e para mudanças/transformação da realidade, novos conhecimentos, evolução e consolidação da ciência. Conclui-se que a qualidade de uma pesquisa está atrelada ao rigor científico/metodológico, entre outras características, mas, além de tudo, deve ser útil para que se possa resolver as situações problemáticas no campo educacional, que muito tem precisado de estudos e trabalhos dos pesquisadores da área.
\end{abstract}

Palavras-chave: Estudos de doutoramento. Pesquisa. Qualidade. Questionário.

\section{ABSTRACT}

This article seeks to present some of the conceptions about the quality of research in education expressed by reamequian@s in the course of the Research in Education Sciences subject of the Doctorate in Science and Mathematics Education at REAMEC, Federal University of Mato Grosso, in 2019. The basic instrument of data collection for the production of this work was a questionnaire proposed to colleagues reamequian@s in a practical activity developed with the class during the socialization of a text that addresses rigor and quality of research in education. Data analysis was based on Bardin. Among the results presented by doctoral students on what research should have to be considered of quality, there were concepts that involved: reliability, impartiality, relevance, moral and ethical values, scientific principles / rigor, analysis of education paths, contributions of the research results to the educational process and to changes / transformation of reality, new knowledge, evolution and consolidation of science. It is concluded that the quality of a research is linked to scientific / methodological rigor, among other characteristics, but, in addition, it must be useful for solving problematic situations in the educational field, which has been in great need of studies and work researchers in the field.

Keywords/: Doctoral studies. Search. Quality. Quiz.

\footnotetext{
${ }^{1}$ Doutoranda do Programa de Pós-Graduação em Educação em Ciências e Matemática pela UFMT, Mestre em Ciências pela UFRRJ. Professora do Instituto Federal de Educação, Ciência e Tecnologia do Tocantins (IFTO), Porto Nacional, Tocantins, Brasil. Av. Tocantínea, $\mathrm{n}^{\circ}$ 566, Porto Nacional, Tocantins, Brasil, CEP: 77500.000 Email: kenya@ifto.edu.br.

${ }^{2}$ Doutora em Educação pela USP. Professora e Coordenadora-Geral do Programa de Pós-Graduação em Educação em Ciências e Matemática da UFMT/UEA/UFPA, Cuiabá, Mato Grosso, Brasil. Av. Fernando Correa da Costa, Bairro: Boa Esperança. Cuiabá, Mato Grosso, Brasil, CEP: 78060-900. E-mail: marponda@uol.com.br.
} 


\section{INTRODUÇÃO}

A Rede Amazônica de Educação em Ciências e Matemática (REAMEC) foi idealizada no ano de 2006 após discussões promovidas em um fórum de pró-reitores de pós-graduações das instituições de ensino superior dos estados da região amazônica: Acre, Amapá, Amazonas, Maranhão, Mato Grosso, Pará, Rondônia, Roraima e Tocantins. Considerando a carência de profissionais na região formados na área, em 2007, em um Workshop na cidade de ManausAM, estruturou-se o primeiro esboço de como seria o Programa de Pós-Graduação em Educação em Ciências e Matemática (PPGECEM). Foi constituída uma Comissão nomeada de REAMEC para garantir os encaminhamentos para elaboração do projeto do Programa de Doutorado do PPGECEM. Entre os objetivos da implementação desse curso destaca-se o de "formar doutores formadores de pesquisadores e professores" para a região da Amazônia Legal ${ }^{3}$ (UFMT, 2012, p.9).

Diante de tal proposta, a Universidade Federal de Mato Grosso em parceria com a Universidade Federal do Pará e a Universidade do Amazonas (como IES Polos), e outras 22 instituições, ofertou no ano de 2010 as primeiras 30 vagas para o doutorado do PPGECEM. A primeira turma teve suas aulas iniciadas em janeiro de 2011. Entre os anos de 2010 e 2016 foram ofertadas para o referido curso o total de 164 vagas, e foram formados, até meados do mês de dezembro de 2019, 130 doutores.

O diferencial do programa é que ele se destina exclusivamente a professores das instituições integrantes da rede, com aulas presenciais em meses como janeiro, fevereiro, junho e julho, fator que pode contribuir para o ingresso do professor no curso, sua permanência nele e seu êxito com a conclusão do doutorado em até quatro anos civis.

No último Edital de Abertura, o de $n^{\circ}$ 01/2019, publicado em junho de 2018 (PPGECEM, 2018), foram disponibilizadas 60 vagas para o referido programa, distribuídas nos três polos onde o curso é ministrado: Cuiabá-MT, Manaus-AM e Belém-PA.

Segundo Darsie (2018), os ingressantes no programa da REAMEC são nomeados reamequian@ $\mathrm{s}^{4}$. A turma 2019 teve início de suas aulas em janeiro do mesmo ano com as disciplinas de Bases Epistemológicas para o Ensino de Ciências e Matemática e Pesquisa em Ciências da Educação. Por se tratar de um programa em que os acadêmicos são professores,

\footnotetext{
${ }^{3}$ A meta descrita no Projeto Básico do PPGECEM/REAMEC era de formar 150 doutores até o ano de 2020.

${ }^{4}$ A opção de uso do sinal de arroba (@) foi por nós incluída para identificar que se trata na palavra tanto o gênero feminino como masculino. A simbologia tem o mesmo sentido em quaisquer outras palavras em que se utiliza a expressão @. Já a denominação reamequianos foi definida pela professora Darsie.
} 
observa-se a importância de destacar os conhecimentos prévios destes. Logo, entende-se que o conhecimento se consolida em um processo de construção, em um antes e depois da realização de um curso de doutorado, por exemplo.

Busca-se neste estudo obter respostas para os seguintes questionamentos: qual(is) concepção(ões) de pesquisa em educação de qualidade expressas por reamequian@s antes e depois da discussão sobre essa temática em aula do curso de doutorado do PPGECEM/REAMEC? Segundo eles, quais características definem a qualidade de uma pesquisa em educação?

O presente artigo visa apresentar algumas das concepções sobre a qualidade de uma pesquisa em educação expressas por reamequian@s, a partir de atividade proposta em aulas de Pesquisa em Ciências da Educação da REAMEC, em 2019. A disciplina foi ministrada, no polo de Cuiabá, por professoras da Universidade Federal de Mato Grosso, entre os dias 11 de fevereiro a $1^{\circ}$ de março. Os estudos e discussões promovidos durante as aulas deram base para o desenvolvimento das reflexões apresentadas neste texto. $\mathrm{O}$ instrumento de coleta de dados para a produção deste trabalho foi um questionário proposto aos colegas reamequian@s (os que cursaram a disciplina no polo Cuiabá), em uma atividade prática desenvolvida com a turma durante a socialização de André (2001), que aborda sobre o rigor e qualidade de pesquisa em educação.

A REAMEC forma professores que, por sua vez, formam novos pesquisadores. Levantar as concepções que esses futuros doutores têm sobre uma pesquisa educacional de qualidade foi uma forma de promover o debate a respeito das compreensões que os mesmos tinham sobre pesquisa, permitindo assim uma reflexão que pode contribuir, também, para que @ leitor(a) deste trabalho analise as suas considerações sobre o que deve ter uma pesquisa em educação para ser classificada como de qualidade.

No próximo item deste artigo socializam-se algumas definições sobre os termos: conhecimento e ciência, Reflexões Iniciais. No item seguinte, apresenta-se uma revisão teórica sobre Pesquisa em Educação, dando destaque à história da pesquisa em educação no Brasil, às abordagens epistemológicas e tipos de pesquisa, bem como às concepções de pesquisa qualitativa e pesquisa de qualidade. Na Metodologia esclarece-se sobre os procedimentos adotados para o desenvolvimento da atividade que resultou na produção deste trabalho. Apresentam-se em seguida os Resultados e Discussões, e, por fim, tecem-se as Considerações Finais, que antecedem as Referências utilizadas neste trabalho. 


\section{REFLEXÕES INICIAIS: DEFININDO CONHECIMENTO E CIÊNCIA}

Antes de iniciar a disciplina de Pesquisa em Ciências da Educação, foi proposto aos reamequin@s, turma 2019, buscar definir os conceitos de conhecimento e ciência a partir das seguintes reflexões: o que é conhecimento? O que é ciência? A ciência é, ou não, possível? Como a ciência é possível?

Acredita-se que conhecer é tornar para si um saber de modo teórico e prático. Enquanto o conhecimento é o entendimento do sentido que determinado assunto/objeto/sujeito evidencia, é o domínio sobre algo no qual se pode agir.

Japiassú e Marcondes (2001, p. 40) apresentam a definição de conhecimento como "uma apropriação intelectual de determinado campo empírico ou ideal de dados, tendo em vista dominá-los e utilizá-los”. Ao conhecimento estão atrelados o ato e o fato de conhecer.

Os mesmos autores conceituam a ciência como um saber, um conjunto de conhecimentos metodicamente adquiridos e sistematicamente organizados.

Acredita-se que nem todo conhecimento é ciência, todavia, toda ciência tem como base o conhecimento, pois, para ser considerado científico, deve ter passado pelo crivo da investigação e do método, pela pesquisa.

Compreende-se que a ciência, além de ser um campo amplo de estudo sistematizado, é, ao mesmo tempo, o resultado dele. Dessa forma, é possível ao indivíduo fazer ciência, cabendo ao homem pôr em questionamento as certezas que o conhecimento aparentemente apresenta.

Precisa-se da ciência e somente se sobrevive porque a ciência existe. Os conhecimentos advindos do desenvolvimento da ciência, como afirmados por Japiassú e Marcondes (2001), são suscetíveis de serem transmitidos por um processo pedagógico de ensino. Além disso, observa-se que os resultados dos estudos científicos estão em diversas áreas de aplicação, aprimorando, por exemplo, os trabalhos em educação e saúde. É a ciência que contribui para que se viva melhor e este deve ser o seu principal objetivo: garantir qualidade de vida à humanidade.

A existência de novos pesquisadores e doutores no Brasil é uma das possibilidades de haver ciência, além de ser a garantia de melhorias em áreas cruciais para a preservação da existência humana.

Diante de tais reflexões, cabe compreender o processo histórico da pesquisa em educação no Brasil. Existiriam características que definiriam uma pesquisa em educação de qualidade? 


\section{PESQUISA EM EDUCAÇÃO}

Com o intento de revisitar algumas das aprendizagens obtidas no estudo da disciplina de Pesquisa em Ciências da Educação, nesse item abordar-se-ão André (2001; 2013), Clandinin e Connelly (2015), Desgagné (2007), Gamboa (2012; 2003), Gatti (2005), Gomes (2019), Monteiro (2019) e Tripp (2005).

Inicia-se com um breve histórico sobre a pesquisa em educação no Brasil, em seguida discorre-se sobre algumas abordagens epistemológicas e tipos de pesquisa e, por fim, apresentam-se, com foco em André (2001) e Gamboa (2003, 2012), algumas concepções sobre pesquisa qualitativa e pesquisa de qualidade.

\subsection{Breve histórico da pesquisa em Educação no Brasil}

A pesquisa em educação no Brasil iniciou com incentivos da criação do Instituto Nacional de Pedagogia ${ }^{5}$ em 1937, embora em décadas anteriores constem em registros tentativas para sistematização de conhecimentos no âmbito educacional (INEP, 2019).

Até o golpe militar de 1964 as pesquisas em educação no Brasil tinham como abordagens principais os estudos psicopedagógicos e sociológicos. A base de conhecimentos dos pesquisadores vinha do exterior, até devido ao fato de, entre o corpo docente daquela época, ter visitantes do exterior e brasileiros que estudaram em outro país. Os primeiros programas de pós-graduação no Brasil surgiram na segunda metade da década de 60 , em concentração nos estados do Rio de Janeiro e São Paulo. No final da década de 70 foi criada no Brasil a Associação Nacional de Pós-Graduação e Pesquisa em Educação - ANPED. Os dois acontecimentos possibilitaram o fortalecimento da pesquisa e a produção acadêmica, principalmente, nas regiões Sul e Sudeste do país. Em 1974, a atual Coordenação de Aperfeiçoamento de Pessoal de Nível Superior - CAPES (que existia com outra nomenclatura desde 1951) foi reestruturada, passando a constar no seu estatuto como órgão central superior, tendo autonomia inclusive financeira. No final dessa década, a área de Ensino de Ciências e Matemática teve financiamentos específicos, sendo fortalecida também pela implementação de programas com vistas à Formação de Professores para o Ensino Superior, embora se possa considerar que os financiamentos na área da Educação ao longo dos anos foram tênues quando comparados a outras realidades. (CAPES, 2019).

\footnotetext{
${ }^{5}$ Atualmente o INEP denomina-se Instituto Nacional de Estudos e Pesquisas Educacionais Anísio Teixeira.
} 
Até o final da década de 80 havia a predominância de mulheres com a média de 40 anos realizando pesquisa, segundo relatório de pós-graduação da América Latina, sendo que a falta de financiamento e infraestrutura para a pesquisa no Brasil fez prevalecer os trabalhos exploratórios e estudos de casos. Alguns teóricos passam a estudar gestão e questões como ensino de disciplinas específicas na escola elementar. A partir da década de 90 vê-se que novas preocupações agregam-se às modalidades de pesquisa. Pereira e Silveira (2019) realizaram uma pesquisa para analisar a representatividade da região Norte do país nos trabalhos publicados no Encontro Nacional de Pesquisa em Educação em Ciências (ENPEC) do ano de 2017, e concluíram que as discussões apresentadas pelos pesquisadores tiveram como eixo temáticos, em ordem decrescente de participação, a Formação de Professores de Ciências; o Ensino e aprendizagem de conceitos e processos científicos; Processos e materiais educativos em Educação em Ciências; Educação em espaços não formais e divulgação científica; e Alfabetização Científica e Tecnológica, abordagens CTS/CTSA e Educação em Ciências. Tal pesquisa permite que se observe a amplitude de problemáticas com as quais os pesquisadores do presente século têm estudado.

É um questionamento atual sobre a disseminação e o uso das pesquisas educacionais: publicar para quem? O que fazemos com o que temos produzido nas pesquisas?

\subsection{Abordagens epistemológicas e tipos de pesquisa em educação}

Entre as abordagens epistemológicas nas quais uma pesquisa científica pode se pautar constam: empírico-analítica; fenomenológico-hermenêutica; crítico-dialética e pós-moderna. Para Gamboa (2012), a epistemologia não é uma teoria geral do saber ou conhecimento, mas é parte da filosofia que se ocupa especialmente com o estudo crítico: a ciência como produto e como processo; ao passo que o método é o tipo de processo para se chegar ao objeto.

$\mathrm{Na}$ abordagem empírico-analítica encontram-se metodologias de pesquisa com foco no: experimentalismo, positivismo, funcionalismo e sistemismos. Essa abordagem pauta-se na observação, buscando demonstrar de forma científica se uma hipótese é verdadeira ou não, sendo importante o uso do experimento. Valoriza-se a experiência prática. Sua base epistemológica é Aristóteles ${ }^{6}$. Nela os objetos são tratados como inanimados e distantes do pesquisador (GAMBOA, 2012). Aborda-se a realidade dos fatos que são observáveis,

\footnotetext{
${ }^{6}$ CONCEITO DE MÉTODO EMPÍRICO. Disponível em: https://queconceito.com.br/metodo-empirico-analitico.
} Acesso em: 18 fev. 2019. 
estimáveis e mensuráveis, de um tempo estável e contexto isolado: as partes são "separadas do todo e esse todo é isolado do contexto natural”. (GAMBOA, 2003, p. 401).

$\mathrm{Na}$ abordagem fenomenológico-hermenêutica encontram-se metodologias de pesquisa com foco no historicismo, estruturalismo, interacionismo simbólico, na fenomenologia, na etnografia, na etnometodologia, entre outras. Trata-se de um estudo descritivo dos fenômenos tal qual estes se apresentam a nossa experiência. Deve-se concentrar atenção na coisa em si e não nas teorias. $\mathrm{O}$ tempo é o presente, e a realidade pode ser considerada como um processo instável, dinâmico e incerto. Deve-se compreender o fenômeno sem intenção de compará-lo. Nessa abordagem o foco é o sujeito (a sua linguagem e subjetividade). Analisam-se as partes para o todo dentro do seu contexto que deve ser interativo.

$\mathrm{Na}$ abordagem crítico-dialética, encontram-se metodologias de pesquisa com foco no materialismo histórico e teorias críticas, entre outras, tendo como base o marxismo. A dialética, para Gamboa (2012, p. 38), "[...] é o método que nos permite conhecer a realidade concreta no seu dinamismo e nas inter-relações". O objeto transforma o sujeito quanto o sujeito transforma o objeto. O sujeito é socialmente construído, ativo e transformador, e o objeto, construído socialmente. O tempo é entendido como em transformação, e a realidade analisada a partir do entorno (GOMES, 2019). Logo, para Gamboa (2012, p.39) “[...] A análise da sociedade só pode desenvolver-se na sua totalidade. A tarefa da ciência está orientada para a crítica dos interesses e para a emancipação do homem [...]".

$\mathrm{Na}$ abordagem pós-moderna encontram-se tendências metodológicas do pósestruturalismo, neo-pragmatismo e teorias pós-críticas. Baseia-se na causalidade complexa. A mediação entre o sujeito e a realidade envolve "idiossincrasias, humores, linguagens e códigos, símbolos novos, trocas inusitadas". (GATTI, 2005, p.147). O objeto é o texto separado do referente da realidade e do autor, sendo o sujeito deslocado do texto (que pode se tornar palavra). O contexto envolve cenários múltiplos, virtuais, deslocados, havendo a negação do tempo como um presente ilimitado.

Considerando o resumo das abordagens epistemológicas, discorre-se a seguir sobre alguns dos tipos de pesquisas discutidos no decorrer das aulas de Pesquisa em Ciências da Educação. Busca-se apresentar, de forma pontual, algumas características de estudo de caso, pesquisa-ação, etnografia, pesquisa colaborativa e pesquisa narrativa.

Na pesquisa em educação pode-se optar pelo estudo de caso, que consiste em estudar intensamente um ou poucos casos. Ele tem caráter holístico e interpretativo. Visa-se compreender cada caso em seu contexto e com múltiplas variáveis. (ANDRÉ, 2013). 
Dependendo da similaridade das condições particulares e contextuais do caso analisado, as conclusões podem ser extrapoladas ou transferíveis, desde que se tenha uma teoria prévia.

A pesquisa-ação é uma forma de investigação-ação que pode alterar o objeto pesquisado, sendo limitada pelo contexto e pela ética da prática. (TRIPP, 2005). Nela, três fases são fundamentais: o planejamento, a ação e a análise dos resultados da ação que pode ser retomada como ação. (LEWIN, 1946 apud TRIPP, 2005). Uma proposta de pesquisa-ação deve, entre outras situações, tratar de assuntos de interesses entre as partes, permitir que todas as partes envolvidas participem ativamente da atividade, sendo o resultado dela benéfica a todos.

Em contraste com a pesquisa-ação tem-se a etnografia. Nela não se pode pretender mudar o ambiente pesquisado. A ênfase é atribuída no processo e no objeto da pesquisa (não no produto ou nos resultados). Entre técnicas que podem ser utilizadas constam: observação, entrevista, análise de documentos, permitindo outros tipos de instrumentos. O pesquisador é a mediação principal na coleta e análise de dados. Ele deve apreender e retratar a visão pessoal dos participantes (os significados atribuídos por eles culturalmente a partir de sua visão e experiência). É importante ressaltar que existe a pesquisa etnográfica e o estudo do tipo etnográfico, cuja existência é defendida por André (1995). A pesquisa etnográfica tem como foco entender a cultura de comunidades e grupos sociais, não precisa de hipóteses e, é, por natureza, fenomenológica. (GOMES, 2019). O estudo do tipo etnográfico se diferencia da pesquisa etnográfica na medida em que utiliza a etnografia de forma instrumental, como uma técnica de coleta de dados. André (1995) acredita que a principal preocupação dos estudiosos da educação é com o processo educativo, e, devido a este fator, tem-se adaptado a etnografia à educação, o que faz com que requisitos da etnografia não sejam cumpridos frente a questões educacionais. Diante de tal contexto, considera-se que na educação tem-se realizado estudos do tipo etnográfico.

Na pesquisa colaborativa os envolvidos trabalham conjuntamente em um processo de construção (e mediação) de um objeto do conhecimento entre pesquisador e participantes. Ela é, ao mesmo tempo, atividades de produção de conhecimentos e de desenvolvimento profissional. (DESGAGNÉ, 2007).

A pesquisa narrativa surge na França por meio de estudos que envolviam movimentos biográficos e autobiográficos. Pensa-se e relata-se sobre a experiência em um ciclo de viver, contar, reviver e recortar. O pesquisador parte de uma relação de interação com o pesquisado. (MONTEIRO, 2019). A pesquisa narrativa é o estudo da experiência como história, podendo ser método de pesquisa e ao mesmo tempo o fenômeno pesquisado. (CLANDININ; CONNELLY, 2015). 
Os tipos de pesquisa discorridos neste item também podem ser classificados como pesquisa qualitativa, abordagem essa que é frequentemente utilizada na área da educação/ensino.

\subsection{Pesquisa Qualitativa e Concepções de Pesquisa em Educação de Qualidade}

Quando se estuda sobre pesquisa em educação, uma das discussões constantemente levantada refere-se ao conceito Pesquisa Qualitativa. Logo, entende-se que a escolha pela abordagem qualitativa em trabalhos da área da educação e do ensino é predominante devido às proposições das problemáticas que surgem no contexto educacional, que, além de complexas, demandam do pesquisador uma análise crítico-reflexiva de dados que, somente usando uma abordagem quantitativa, podem não ser compreendidos.

Atrelada ao debate da Pesquisa Qualitativa também se encontra a discussão sobre Pesquisa em Educação de Qualidade.

Para André (2001, p.55) a pesquisa qualitativa envolve estudos que podem englobar "um conjunto heterogêneo de perspectivas, de métodos, de técnicas e de análises, compreendendo desde estudos do tipo etnográfico, pesquisa participante, estudos de caso, pesquisa-ação até análises e de narrativas, estudos de memórias, história de vida e história oral”.

Gamboa (2003) afirma que é preciso superar o falso dualismo quantitativo e qualitativo de uma pesquisa, pois as formas de gerar conhecimento não se esgotam neles. Critica o fato de que, no início do século XXI, muitos cursos de formação de pesquisadores tenham retirado do seu programa disciplinas como estatísticas, e afirma que o fato de ter ou não tal disciplina não anula a concepção de ciência predominante na pesquisa educacional. Para ele, "[...] identificar a pesquisa como qualitativa apenas por desprezar o tratamento estatístico anula as suas dimensões epistemológicas" (p. 403).

É possível uma análise quantitativa em uma pesquisa qualitativa? Entende-se que uma pesquisa de abordagem qualitativa também pode usar de dados quantitativos como meio para que se possa alcançar os resultados esperados, e, com base neles, pode-se tecer as análises do trabalho com enfoque qualitativo, ou seja, considerando-se, entre outros aspectos, o contexto no qual tais dados quantitativos surgiram.

E o que é uma pesquisa de qualidade? Existiriam características que definiriam a qualidade de uma pesquisa em educação? Acredita-se que o termo qualidade, embora tenha um significado comum para todos, é uma expressão que envolve sentidos diferentes para cada pessoa. Logo, a depender da compreensão que o indivíduo tenha do seu entorno e sobre os 
sujeitos e objetos, a qualidade torna-se uma palavra de cunho subjetivo. Todavia, ao ler sobre a pesquisa qualitativa no Brasil, percebeu-se que autores como André (2001) e Gamboa (2003, 2012) indicaram em seus textos algumas das características que consideram como as que devem pertencer a uma pesquisa de qualidade.

Para Gamboa (2003, p. 404): “As pesquisas de boa qualidade têm em comum a abordagem dos problemas prementes da realidade, a clareza na formulação das perguntas e o rigor na construção das respostas que permitem a elaboração de um diagnóstico exaustivo sobre essa realidade".

Ainda segundo Gamboa (2003), uma pesquisa de qualidade deve iniciar-se por uma pergunta que não tenha respostas dadas e que pesquisas anteriores não tenham respondido, somente depois pensa-se nas técnicas de tratamento e sistematizações de dados e informações (devendo o pesquisador assegurar o rigor científico); por fim, deve-se interpretar os dados à luz do referencial teórico. Para o autor, o tempo é um dos entraves para o desenvolvimento de uma boa pesquisa.

André (2001) promove o debate sobre o que se considerar como uma "boa" pesquisa, questionando sobre os critérios que possam ser utilizados para julgar a pesquisa em educação, e quem definiria esses critérios, ao mesmo tempo em que coloca em dúvidas se esses critérios serviriam para qualquer pesquisa. A autora cita que, desde a década de 90, estudiosos vem discutindo as pesquisas em educação, e menciona o trabalho de um grupo de pesquisadores da Academia Nacional Norte-Americana ${ }^{7}$ que levaram oito anos para chegar à conclusão de que, para garantir a qualidade da pesquisa em educação, "é preciso promover o debate nas universidades, nas escolas, nas agências de fomento, nas revistas, na internet, de modo a criar meios para que se possa emergir concepções do que seja uma 'boa' ou uma 'má' pesquisa" (p.52).

Gamboa (2012) levanta a reflexão sobre o fato de alguns estudos investigativos assumirem como pauta o cumprimento de um requisito acadêmico, o que pode fazer com que a pesquisa perca capacidade de ser um instrumento para conhecer a problemática da realidade, deixando, pois, de ter uma dimensão transformadora. Tal fato implica afirmar que uma boa pesquisa deve ter como base resolver uma problemática, de modo a, assim, transformar a realidade observada. $\mathrm{O}$ autor afirma que o êxito de uma pesquisa de qualidade pode estar na articulação entre as técnicas e suas relações com os métodos e os procedimentos, bem como

\footnotetext{
${ }^{7}$ Segundo André (2001, p.52), entre esses pesquisadores estavam: Charles Bidwell, Ann Brown, Jeome Bruner, Allan Collins, Ellen Langeman e Lee Shulman.
} 
"no conhecimento dos pressupostos e das implicações da abordagem epistemológica que o pesquisador utiliza" (p.53). O pesquisador deve saber quais são suas bases epistemológicas, pois as mesmas têm influência na análise dos dados e nos resultados.

Gamboa (2003, p. 405) lembra que: “[...] É prioridade nos debruçarmos sobre a qualidade da pesquisa produzida no país e identificar as suas contribuições na compreensão da problemática da sociedade brasileira".

No bojo dessa discussão, André (2001) apresenta algumas características consideradas em uma pesquisa em educação de qualidade. Segundo a autora, entre os critérios utilizados para julgar a pesquisa em educação estão:

a) "a relevância científica e social". O trabalho deve estar inserido em um quadro teórico em que fiquem evidentes sua contribuição ao conhecimento já disponível e a temas engajados na prática social (p. 59);

b) a análise "densa, fundamentada trazendo as evidências e as provas das afirmações e conclusões". O conhecimento novo deve estar em evidência (p.59);

c) o objeto bem definido. As pesquisas devem ter objetivos ou questões claramente formulados, "metodologia adequada aos objetivos, procedimentos metodológicos suficientemente descritos e justificados" (p.59).

Cabe ressaltar que os critérios mencionados nas alíneas "a", "b" e "c" são alguns dos requeridos pelo CNPQ/Capes/Fapesp ${ }^{8}$ para analisar de forma geral os trabalhos científicos. André (2001) alerta para a necessidade de pensar em critérios específicos para avaliação das pesquisas considerando o seu tipo. Cita como exemplos critérios que devem ser observados nas pesquisas de estudos etnográfico e em pesquisa-ação.

\begin{abstract}
Nos estudos etnográficos os critérios específicos analisados são: a) o papel da teoria na construção das categorias; b) a necessidade de se respeitar princípios da etnografia, como a relativização (centrar-se na perspectiva do outro) e o estranhamento (esforço deliberado de análise do familiar como se fosse estranho); c) o desenvolvimento do trabalho de campo com apoio em observação planejada e em instrumentos e registros bem elaborados". [...] Na pesquisa-ação há a necessidade do tratamento adequado da subjetividade; a importância que se distinga ação e pesquisa; e que as questões e que as questões relacionadas à ética sejam enfrentadas diretamente. Indagamos: quais os mecanismos de controle da subjetividade? Como se dá o processo de participação? Quem decide o que vai ou não ser publicado: Como são feitos o controle e a sistematização dos dados? (ANDRÉ, 2001, p.59, grifo nosso).
\end{abstract}

${ }^{8}$ CNPQ - Conselho Nacional de Desenvolvimento Científico e Tecnológico - Capes - Coordenação de Aperfeiçoamento do Pessoal de Nível Superior - Fapesp- Fundação de Amparo à Pesquisa. 
Concorda-se com André (2001) e com Gamboa (2003, 2012) sobre a importância de se discutir sobre a "boa" pesquisa. Logo, essa compreensão, como indica os autores, pode contribuir para amenizar as situações problemáticas encontradas na sociedade brasileira.

Cabe ressaltar que tais descrições são as concepções que estes autores têm sobre pesquisa de qualidade. E que concepção, conforme esclarece Japiassú e Marcondes (2001), é uma operação pela qual o entendimento forma o conceito, sendo que esse entendimento se dá por meio da experiência física, moral, psicológica ou social e pela representação com que o determinado conceito se apresenta a ele. Definição essa que permite que se conclua que qualidade e qualidade de uma pesquisa em educação podem ter vários sentidos e características, a depender do indivíduo (órgão, conselho, coordenação) que as apresente e defenda.

Considerando que estudantes de curso de pós-graduação produzem conhecimento, bem como possuem um entendimento sobre vários conceitos, independente de estudar sobre determinado tema, questiona-se: quais as concepções d@s reamequian@s sobre pesquisa em educação de qualidade? Haveria mudanças nos conceitos sobre a qualidade de uma pesquisa partir do que se discutiu, em aula, sobre o tema?

\section{METODOLOGIA}

A metodologia das aulas de Pesquisas em Ciências da Educação consistia, entre outras atividades, de: leitura e socialização de artigos, discussão sobre teses já defendidas por meio da participação de professores visitantes, bem como análise de teses e discussão sobre elas promovidaspel@sdoutorand@s.

Diante da proposição de discussão do texto de André (2001), em uma das aulas da disciplina supracitada, a do dia 14 de fevereiro de 2019, propôs-se um questionário aos colegas reamequian@s contendo duas perguntas, uma que deveria ser respondida antes da apresentação do texto "Pesquisa em Educação: buscando rigor e qualidade" e outra pergunta que foi respondida depois da discussão do referido texto.

As perguntas foram:

C1) Na sua opinião o que é uma Pesquisa (em Educação) de Qualidade? O que deve ter uma pesquisa para ela ser considerada "de qualidade"?

C2) Após a discussão do texto de André (2001), você corroboraria a definição de Pesquisa de Qualidade descrita no C1? Há alguma característica para a Pesquisa de Qualidade a acrescentar na sua definição? Qual(is)? (LOPES; CUNHA, 2019). 
No instrumento entregue aos colegas, esclareceu-se que a participação deles ao responder às questões colaboraria com a discussão levantada por André (2001). Excluindo as três acadêmicas que estavam envolvidas diretamente com o desenvolvimento da atividade, (duas expositoras e uma debatedora), do total de 14 doutorand@s, responderam ao questionário 10 reamequian@ $\mathrm{s}^{9}$.

Buscou-se com a atividade promover o debate com os pesquisadores e professores, tal como sugerido pelos autores André (2001) e Gamboa (2003, 2012), sobre o que é uma "boa" pesquisa.

Do ponto de vista da abordagem proposta e do procedimento utilizado durante a atividade, acredita-se que a mesma pode ser classificada como qualitativa. A análise dos resultados dos questionários foi pautada em Bardin (2011). Segunda a autora, tal análise visa obter, por meio de procedimentos sistemáticos e objetivos de descrição do conteúdo dos dados, indicadores que permitam a inferência de conhecimentos relativos às condições pesquisadas. A análise de conteúdos está organizada nas fases: a) organização da análise, b) codificação; c) categorização; d) tratamento dos resultados, inferência e interpretação dos resultados. A primeira fase é composta pela pré-análise, exploração do material, tratamento e interpretação dos resultados.

\section{RESULTADOS E DISCUSSÕES}

Dez reamequian@s responderam ao instrumento proposto em aula. Para divulgação dos resultados, os mesmos foram nomeados com o código iniciado com a letra " $\mathrm{R}$ 10" seguido de um número, a exemplo: "R1."

Entre as respostas apresentadas pel@s reamequian@s para as perguntas: "Na sua opinião o que é uma Pesquisa (em Educação) de Qualidade? O que deve ter uma pesquisa para ela ser considerada “de qualidade"?", constaram conceitos que envolviam: confiabilidade (1) imparcialidade (1), relevância (2), valores morais (1) e éticos (3), princípios/rigor científicos (3), análise dos caminhos da educação (1), contribuições do resultado da pesquisa para o

\footnotetext{
${ }^{9}$ A turma 2019 da REAMEC - polo UFMT possui o total de 17 doutorand @ s, sendo 12 deles da Linha de Pesquisa de Formação de Professores e 5 deles da Linha de Pesquisa de Fundamentos e Metodologias para a Educação em Ciências e Matemática. Nessa disciplina participaram os 17 doutorand@s do polo.

10 A letra se refere ao termo reamequian@.

${ }^{11} \mathrm{O}$ número representa, segundo a análise das autoras, a quantidade de vezes que tal termo foi apontado entre as respostas dos colegas, o que implica afirmar que em uma resposta pode haver vários conceitos apresentados entre os que foram categorizados nesse parágrafo.
} 
processo educativo (7) e para mudanças/transformação da realidade (3), novos conhecimentos

(1), evolução e consolidação da ciência (3).

Para melhor compreensão das concepções apresentadas pelos colegas antes e depois da discussão do texto de André (2001), transcreveram-se as respostas no Quadro 1 a seguir.

\begin{tabular}{|c|c|}
\hline $\begin{array}{l}\text { Resposta ao Conceito (C1) } \\
\text { O que é e o que deve ter uma pesquisa de } \\
\text { qualidade? }\end{array}$ & $\begin{array}{l}\text { Resposta ao Conceito (C2) } \\
\text { Alguma definição de pesquisa de qualidade a acrescentar } \\
\text { após discussão do texto de André (2001)? }\end{array}$ \\
\hline $\begin{array}{l}\text { "Seja relevante, siga os códigos de ética, traga } \\
\text { contribuições para os sujeitos da pesquisa, utilize a } \\
\text { norma culta da Língua Portuguesa". (R1) }\end{array}$ & $\begin{array}{l}\text { "Eu continuo compactuando com as informações [...], mas agora } \\
\text { ciente que a qualidade depende do ponto de vista e que o termo } \\
\text { qualidade é complicado de ser usado nas redações de tese, pois } \\
\text { envolve muita subjetividade". (R1) }\end{array}$ \\
\hline $\begin{array}{l}\text { "Ela deve ser confiável (verdadeira na descrição, seguir } \\
\text { um rigor metodológico na execução). Ela deve ser } \\
\text { potencialmente benéfica para evolução da comunidade } \\
\text { científica ou para prática educativa". (R2) }\end{array}$ & $\begin{array}{l}\text { "Não alterei muito minha visão, poderia refinar a escrita, mas o } \\
\text { que acrescentaria seria a criticidade do panorama social no qual } \\
\text { a pesquisa se desenvolve como fator de qualidade". (R2) }\end{array}$ \\
\hline $\begin{array}{l}\text { "A pesquisa de educação de qualidade deve propiciar } \\
\text { uma transformação da realidade, ou do contexto em que } \\
\text { ela está inserida. Além disso, deve possibilitar o avanço } \\
\text { da ciência, respeitando os valores morais e princípios } \\
\text { que regem a comunidade dos sujeitos investigados". } \\
\text { (R3) }\end{array}$ & $\begin{array}{l}\text { "Acrescentaria que a pesquisa deve contribuir para a produção de } \\
\text { conhecimentos científicos relevantes e que apresente uma } \\
\text { relevância social". (R3) }\end{array}$ \\
\hline $\begin{array}{l}\text { "Inicialmente, buscar não fazer mais do mesmo. } \\
\text { Entender que a pesquisa deve efetivamente contribuir } \\
\text { de alguma forma na compreensão e crescimento de } \\
\text { determinado 'assunto' ou 'buracos' ainda não bem } \\
\text { resolvidos". (R4) }\end{array}$ & $\begin{array}{l}\text { "Concordo em termos, e escreveria da seguinte maneira: para } \\
\text { uma pesquisa de qualidade é importante promover debates e } \\
\text { discussões em diferentes 'ambientes' para que se possa emergir } \\
\text { na concepção de boa ou má pesquisa. - Relevância científica e } \\
\text { social, - Análise densa e fundamentada, - A questão que não tem } \\
\text { resposta evidente. - Relevância. - Rigor metodológico". (R4) }\end{array}$ \\
\hline $\begin{array}{l}\text { "Pesquisa que contribua para analisar os caminhos e as } \\
\text { contribuições da Educação na Formação Humana e no } \\
\text { Processo Evolutivo da Humanidade. Para tanto, a } \\
\text { pesquisa deve abordar temáticas que são problemáticas } \\
\text { inerentes ao processo educativo". (R5) }\end{array}$ & $\begin{array}{l}\text { "A Pesquisa necessita ter uma organização que atenda à natureza } \\
\text { do tema/objeto a ser estudado. Ter o cuidado de focar no } \\
\text { problema e objetivo a ser alcançado, escolher revisão } \\
\text { bibliográfica que contribua efetivamente para a tese } \\
\text { (conhecimento científico) a ser construído. A pesquisa deve ser } \\
\text { autêntica e de referência para outras pesquisas e também para a } \\
\text { sociedade, principalmente para o contexto de onde se originou a } \\
\text { pesquisa". (R5) }\end{array}$ \\
\hline $\begin{array}{l}\text { "Pesquisa em Educação relaciona-se à investigação de } \\
\text { problemáticas vivenciadas no contexto da Educação } \\
\text { seja ela na formação inicial, Ed. Básica, Formação } \\
\text { Continuada e/ou em áreas específicas das áreas de } \\
\text { conhecimento. Precisa apresentar um rigor científico } \\
\text { que garanta e/ou consolide a ciência e/ou resultado } \\
\text { divulgado". (R6) }\end{array}$ & $\begin{array}{l}\text { "Relevância científica e social da pesquisa; Constituição de } \\
\text { instrumentos teóricos e metodológicos que dê rigor aos } \\
\text { parâmetros desenvolvidos na pesquisa". (R6) }\end{array}$ \\
\hline $\begin{array}{l}\text { "Onde o resultado é aplicado e promove mudança. O } \\
\text { caminho percorrido para chegar ao resultado." (R7) }\end{array}$ & "Sim. Sim, acrescentaria as citadas pela autora". (R7) \\
\hline $\begin{array}{l}\text { "É aquela que busca atingir as respostas propostas pelo } \\
\text { problema do projeto de pesquisa. Deve ter a } \\
\text { imparcialidade, ética e sem influência ideológica". (R8) }\end{array}$ & “Sim. Poderia acrescentar o rigor metodológico”. (R8) \\
\hline
\end{tabular}
problema do projeto de pesquisa. Deve ter a 
"Que se destaca no conceito de melhor, que atinge os padrões impostos pela maioria como o correto, a ser seguido e que beneficia a maioria com os seus resultados". (R9)
"Em partes eu corroboro. No caso de alguns padrões de 'qualidade' não se leva em consideração o caráter subjetivo de quem criou ou ajudou a criar tais padrões e consequentemente avalia como sendo de qualidade ou não uma pesquisa". (R9)

"Considero que as colocações feitas por C1 não são contraditas pela discussão do texto de Marli André. Essas foram enriquecidas por outros termos. Desta forma, poderia dizer que a leitura do texto enriqueceu o meu "conhecimento" sobre o que seria uma pesquisa "de qualidade". Algumas colocações trazidas pelo texto foram fundamentais para o acréscimo das definições que apresentei inicialmente. A qualidade da pesquisa em educação por vezes se apresenta vinculada a relação de poder, como por exemplo, quem irá financiar ou financia a pesquisa. Para que a pesquisa se apresente de qualidade é necessário, ainda, que ela apresente a estruturação e linguagem própria do campo da ciência. Desta forma, acredito que a pesquisa de qualidade se apresenta dentro de determinados padrões ditados pelos órgãos de fomento, colocando regras que regem a compreensão da chamada Pesquisa de Qualidade. Por último, acredito que a discussão sobre Pesquisa de Qualidade está envolvida em um âmbito maior de imposição, por vezes, de grupos hegemônicos que obrigam a comunidade científica a pensar e agir de maneira pré-determinada, não oferecendo caminhos para outras possibilidades de pensar a pesquisa de qualidade”. (R10)

Quadro 1 - Pesquisa (em Educação) de Qualidade: concepções expressas pel@s reamequian@s. Fonte: Dados da Pesquisa, instrumento proposto por Lopes \& Cunha (2019).

Ao analisar as respostas apresentadas pel@s reamequian@s para as perguntas: “C2) Após a discussão do texto de André (2001), você corroboraria a definição de Pesquisa de Qualidade descrita no C1? Há alguma característica para a Pesquisa de Qualidade a acrescentar na sua definição? Qual(is)?”, observa-se que todos os colaboradores ratificaram o que foi definido em C1, acrescentado critérios apresentados no texto e outros que não estavam explícitos no texto. Entre as respostas atribuídas ao $\mathbf{C 2}$ encontram-se características voltadas para: criticidade do panorama social (2), produção de conhecimentos científicos (1), relevância social e científica (3), análise sobre o termo qualidade (3), rigor teórico e metodológico da pesquisa (3).

Embora os colegas ao responderem ao $\mathbf{C 1}$ não tivessem iniciado o debate do texto de André (2001), observa-se que as definições sobre o que é e o que deve ter uma pesquisa de qualidade aproximam-se (algumas delas são as mesmas) das características apresentadas pela autora. A exemplo, as voltadas para: rigor científico e metodológico, relevância social e científica. Cabe lembrar que, entre os conceitos mais enfatizados pel@s reamequia@s sobre o que deve ter uma pesquisa de qualidade, está o de que uma "boa" pesquisa deve apresentar resultados que possam ter contribuições ao processo educativo e para transformação da realidade. 
O fato de os colegas ratificarem a definição atribuída ao $\mathbf{C 1}$ e apenas acrescentar características ao C2, reforçando, entre outras, as apontadas por André (2001), demonstra que os mesmos possuíam uma base teórica consolidada sobre os caminhos percorridos para o desenvolvimento de uma "boa" pesquisa.

Com base no histórico da evolução das pesquisas em educação apresentadas por André (2001), nas experiências tidas com o desenvolvimento de pesquisa, no debate proposto em aula, e, após análise das concepções apresentadas pel@s reamequian@s, considera-se que uma pesquisa de educação em qualidade deve ter:

a) O olhar do pesquisador (e para isso é importante que ele estude sobre temas que, além de demandarem pesquisas, revelem-se prazerosos quanto à leitura e à análise de dados);

b) A pergunta adequada, a questão que não tem resposta evidente (cabe uma proposta inovadora de pesquisa, aquela que pode garantir um diferencial entre os trabalhos acadêmicos);

c) A relevância científica e social (deve estar atrelada ao que você pesquisa, mas acima de tudo deve atender o "outro");

d) A adoção de forma crítica de uma literatura e teoria de qualidade;

e) O equilíbrio entre ação e investigação;

f) A sistematização e controle de dados;

g) Validade (diretamente ligado a ela está o rigor científico/metodológico).

Concorda-se com o que a maioria d@s reamequian@s definiu em C1 sobre o que deve ter uma pesquisa em educação de qualidade: deve apresentar, sobretudo, resultados que possam garantir melhorias sobre a realidade estudada.

\section{CONSIDERAÇÕES FINAIS}

Promover o debate sobre a qualidade de uma pesquisa logo no início de um curso de Doutorado em Educação em Ciências e Matemática é uma maneira para que se procure desenvolver a pesquisa na área em busca de uma qualidade, seja ela subjetiva, seja ela com critérios definidos pelos órgãos e/ou conselhos responsáveis por primar pelo bom desenvolvimento de trabalhos científicos.

Acreditar que a discussão do trabalho de André (2001) mudaria e/ou acrescentaria novos conceitos nas concepções d@s reamequian@s sobre pesquisa de qualidade, por meio de uma 
proposta de questionário, foi ousada, e de certa forma, necessária. Logo, cabe lembrar que se vive em um mundo em constante mudança e que concepções sobre pesquisa em educação de qualidade tecidas hoje podem não ser as mesmas no amanhã. Propor o debate sobre esse tema em cursos de formação de pesquisadores torna-se imprescindível para se manter trabalhos científicos com padrões de qualidade no Brasil (principalmente na área da educação e do ensino que possuem sérias questões a serem problematizadas), como lembram André (2001) e Gamboa (2003, 2012).

As discussões promovidas nas aulas da disciplina Pesquisa em Ciências da Educação, inclusive as que propuseram análise de teses pel@s doutorand@s, tornaram-se incentivos para se pensar quais caminhos deve-se traçar e seguir para que os problemas levantados nos projetos apresentados pela turma 2019 culminem em resultados com contribuição social, preferencialmente. Entende-se que uma pesquisa de qualidade deve ter rigor científico, mas, além de tudo, deve ser útil para que se possa resolver as situações problemáticas no campo educacional, que muito tem precisado de estudos e trabalhos dos pesquisadores da área.

Se este artigo pode ser considerado como de qualidade por ter características que se enquadrem como um trabalho científico possível de ser publicado em um periódico não se sabe. Logo, dependerá da avaliação da Comissão Editorial do local a ser enviado, pois são os critérios que os mesmos usam que os permitem considerar um trabalho como bom ou não. Todavia, levando-se em consideração a relevância para os pesquisadores que os estudos sobre o tema pesquisa e qualidade possui, acredita-se que o presente trabalho tem qualidade.

O debate do artigo de André (2001) com @s colegas reamequian@s foi uma experiência que resultou em aprendizagens significativas para a formação como pesquisadoras.

\section{REFERÊNCIAS}

ANDRÉ, M. Etnografia da prática escolar. Campinas, SP: Papirus: 1995.

ANDRÉ, M. O que é um estudo de caso qualitativo em educação? Revista da FAEEBA Educação e Contemporaneidade, Salvador, v. 22, n. 40, p. 95-103, jul./dez. 2013.

ANDRÉ, M. Pesquisa em Educação: buscando rigor e qualidade. Cadernos de Pesquisa. n. 113, p.51-64, julho/2001.

BARDIN, L. Análise de Conteúdo. São Paulo: Edição 70, 2011.

CAPES, História e Missão. Disponível em: https://www.capes.gov.br/historia-e-missao Acesso em: 30 mar. 2019. 
CLANDININ, D. J..; CONNELLY, F. M. Pesquisa Narrativa: experiência e história em Pesquisa Qualitativa. 2a Ed. Uberlândia: EDUFU, 2015.

DARSIE, M. M. P. REAMEC [mensagem pessoal]. Mensagem recebida por kenya@ifto.edu.br em: 4 dez. 2018.

DESGAGNÉ, S. (Tradução Adir Luiz Ferreira, Margarete Vale Sousa). O conceito de pesquisa colaborativa: a ideia de uma aproximação entre pesquisadores universitários e professores práticos. Revista Educação em Questão, Natal, v. 29, n. 15, p.7-35, maio/ago. 2007.

FRANÇA, J. L.; VASCONCELLOS, Ana Cristina de. Manual para normalização de publicações técnico-científicas. 7. ed. Belo Horizonte: Ed. UFMG, 2004.

GAMBOA, S. S. Pesquisa em educação: métodos e epistemologias. $2^{\text {a }}$ ed. Chapecó: Argos, 2012.

GAMBOA, S. S. Pesquisa Qualitativa: superando tecnicismos e falsos dualismos.

Contrapontos. Volume 3, n. 3, p.393- 405.Itajaí, 2003.

GATTI, B. Pós-modernidade, educação e pesquisa: confrontos e dilemas no início de um novo século. Psicologia da educação, n.20. São Paulo jun. 2005. Disponível em:

http://pepsic.bvsalud.org/pdf/psie/n20/v20a08.pdf. Acesso em: 18 fev. 2019.

GATTI, B.; ANDRÉ, M. A relevância dos métodos de pesquisa qualitativa em Educação no Brasil. In: WELLER, Wivian; PFAFF, Nicole. Metodologia da Pesquisa Qualitativa em Educação: teoria e prática. Petrópolis: Vozes, 2011.

GOMES, C. F. Meninos e Brincadeiras de interlagos: um estudo etnográfico da ludicidade (Tese de doutorado socializada pelo autor aos reamequian@s). Cuiabá: Registro da aula do PPGECEM do dia 20 fev. 2019 feito por Lopes, 2019.

INEP, História. Disponível em: http://portal.inep.gov.br/historia Acesso em: 30 mar. 2019.

JAPIASSÚ, H.; MARCONDES, D. Dicionário Base de Filosofia. Rio de Janeiro:

Digitalizado por TupyKurumin, 2001.

LOPES, K. M. V.; CUNHA; J. N. F.; Questionários sobre Conceitos de Pesquisa em

Educação de Qualidade. Cuiabá: Instrumento proposto aos reamequian@s em aula do dia 14 fev. 2019.

MONTEIRO, F. M. de A. Pesquisas Narrativas. Cuiabá: Registro da aula do PPGECEM do dia 21 fev. 2019 feito por Lopes, 2019.

PEREIRA, T. Z. M.; SILVEIRA, C. A produção acadêmica da Região Norte: uma análise na ata do XI Encontro Nacional de Pesquisa em Educação em Ciências. REAMEC - Rede Amazônica de Educação em Ciências e Matemática, [S.1.], v. 7, n. 2, p. 245-260, jul/dez, 
2019. ISSN 2318-6674. Disponível em:

http://periodicoscientificos.ufmt.br/ojs/index.php/reamec/article/view/8726/pdf. Acesso em: 25 mar. 2020.

PROGRAMA DE PÓS-GRADUAÇÃO EM EDUCAÇÃO EM CIÊNCIAS E MATEMÁTICA (PPGECEM); REDE AMAZÔNICA DE EDUCAÇÃO EM CIÊNCIAS E MATEMÁTICA (REAMEC). Edital de abertura, no 01/2019, publicado em: 29 jun. 2018. Disponível em:

https://www.ufmt.br/ufmt/site/userfiles/editais/de513bff0991770da2c7d2a58d11349f.pdf Acesso em: 21 ago. 2018.

TRIPP, D. Pesquisa-ação: uma introdução metodológica. Educação e Pesquisa, São Paulo, v. 31, n. 3, p. 443-466, set./dez. 2005.

UNIVERSIDADE FEDERAL DE MATO GROSSO (UFMT). Projeto Básico: Doutorado em Educação em Ciências e Matemática. Cuiabá: Secretaria do PPGECEM/REAMEC, 2012.

Submetido em: 13 de dezembro de 2019.

Aprovado em: 23 de março de 2020. 